ARTICLE

\title{
Vicinal difunctionalization of carbon-carbon double bond for the platform synthesis of trifluoroalkyl amines
}

Ferenc Béke ${ }^{1}$, Ádám Mészáros ${ }^{1}$, Ágnes Tóth$^{1}$, Bence Béla Botlik ${ }^{1}$ \& Zoltán Novák (1D ${ }^{1 凶}$

Regioselective vicinal diamination of carbon-carbon double bonds with two different amines is a synthetic challenge under transition metal-free conditions, especially for the synthesis of trifluoromethylated amines. However, the synthesis of ethylene diamines and fluorinated amine compounds is demanded, especially in the pharmaceutical sector. Herein, we demonstrate that the controllable double nucleophilic functionalization of an activated alkene synthon, originated from a trifluoropropenyliodonium salt with two distinct nucleophiles, enables the selective synthesis of trifluoromethylated ethylene amines and diamines on broad scale with high efficiency under mild reaction conditions. Considering the chemical nature of the reactants, our synthetic approach brings forth an efficient methodology and provides versatile access to highly fluorinated amines. 
T he vicinal diamine backbone is a prevalent motif in natural products, chelating agents, chiral ligands, and pharmaceuticals ${ }^{1,2}$. Nature presents this structural motif in the form of non-proteinogenic amino acids which constitute the skeleton of numerous peptide antibiotics ${ }^{3}$. (Fig. 1a) Along with natural occurrence, the diamine moiety can be found in approved drugs, such as Promethazine, Osimertinib, and Sunitinib which are placed among the most marketed pharmaceuticals 4 . (Fig. 1b) Concurrently, many drug candidates that are investigated in the treatment of chronic pain and metastatic melanoma share the vicdiamine skeleton. Considering the importance of this moiety, the development of methods for the construction of vicinal diamines is an important area of research in organic synthesis ${ }^{1,2}$. Among the various synthetic possibilities of accessing the target diamine molecules, conceptually, the most straightforward way is the direct introduction of nitrogen atoms across a carbon-carbon double bond (Fig. 1c) ${ }^{1,5}$. Indeed, a diverse set of methodologies have been developed to introduce nitrogen atoms attached the same substituents onto carbon-carbon double bond, i.e., diazidation and homodiamination reactions in metal-assisted ${ }^{6,7}$, metal-catalyzed $^{8-13}$, organoselenium-catalyzed ${ }^{14}$, hypervalent iodine-assisted and -catalyzed ${ }^{15-19}$ photochemical ${ }^{20-23}$ and electrochemical ${ }^{24,25}$ fashions.

In general, the diamination reaction of alkenes requires radical or oxidative conditions, which permit the introduction of $\mathrm{N}$ atoms in form of azide, sulfonamide, urea, and amide functionalities, while easily oxidizable alkyl- and aryl-amines are introduced by transition metal-assisted and -catalyzed methods limited to few examples ${ }^{1,26-28}$. Regarding the abundant $\mathrm{N}$-atom sources, nucleophilic difunctionalization of alkenes with simple amines without the use of transition metals would be a cornerstone to improve structural diversity of diamine synthesis. This vicinal amination of the carbon-carbon double bond under metal free conditions has been presented with bifunctional nucleophiles in an intramolecular manner to afford $\mathrm{N}, \mathrm{N}$ - and $\mathrm{N}, \mathrm{O}$-heterocyclic systems using alkenyl-sulfonium salts with two adjacent electrophilic centers ${ }^{29-32}$. However, the intermolecular difunctionalization of alkenes has not been performed by the utilization of two separate external nitrogen nucleophiles via metal-free vicinal heterodiamination. Moreover, the major challenge of the present approach is the selective heterodiamination with two different nitrogen nucleophiles due to the control of reactivity of the nucleophiles and intermediates.

The presence of trifluoromethyl group could fine tune the physical, biological, and chemical properties of organic molecules in medicinal chemistry development ${ }^{33-35}$. Therefore, the incorporation of this structure is an emerging field of synthetic methodology ${ }^{36-40}$. The presence of fluoroalkylamine group in several drug candidates, such as Olinciguat, Cevipabulin, and Odanacatib (Fig. 1d) is essential for high potency, and the bioisosteric relationships to amide and amino acid moieties have been recognized in several instances (Fig. 1e) ${ }^{41-44}$. In this respect, the syntheses of homo- and heterofunctionalized, $a$-trifluoromethyl vicinal diamines ${ }^{45-52}$ and other substituted trifluoropropylamines ${ }^{52-55}$ are demanding.

In this work, we aim to design a versatile selective intermolecular fluorous alkene difunctionalization strategy with the utilization of different nucleophiles to afford valuable functionalized trifluoromethylamines and diamines.

\section{Results}

Optimization and mechanistic studies. For the realization of our goals on selective alkene difunctionalization to obtain trifluoropropyl amines, the presence of an efficient leaving group (LG) was necessary (Fig. 1f). A hypervalent iodonium moiety ${ }^{56-63}$ could be an appropriate choice for LG, due to its super leaving

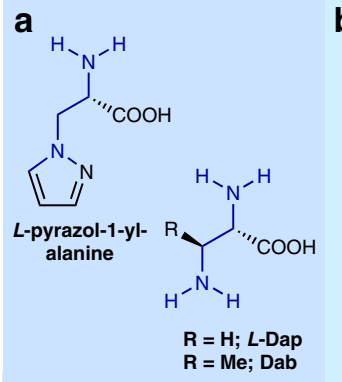

C

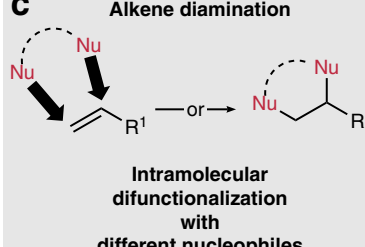

different nucleophiles

$\mathrm{Nu}=\mathrm{N}_{3}, \mathrm{NTs}$, urea- $\mathrm{N}$, amide- $\mathrm{N}$ or other $N, C, O, S$

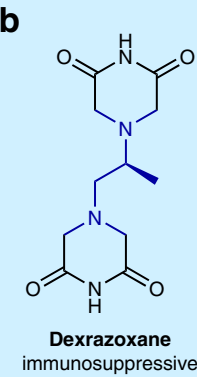

d

d

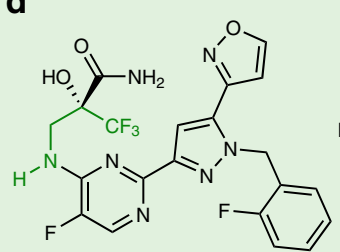

Olinciguat

Sickle cell disease

soluble guanylate cyclase stimulator

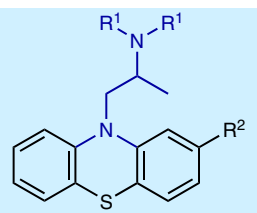

Promethazine $\left(R^{1}=M e, R^{2}=H\right)$ rhinitis, allergy, antihistamine Propiomazine $\left(R^{1}=M e, R^{2}=C O E t\right)$ Antipsychotic, antihistamine

Profenamine $\left(R^{1}=E t, R^{2}=H\right)$

Parkinson's disease, anticholinergic
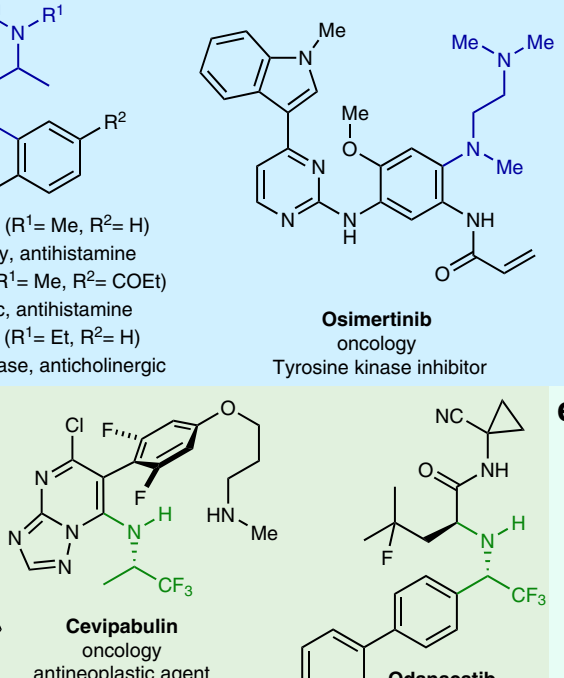

antineoplastic agent oncology
Tyrosine kinase inhibitor

e

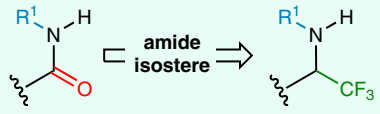

f<smiles>[R]N([Tl])CC(N([R])[3H])C(F)(F)F</smiles><smiles>[R]N([3H])C(CN([2H])[Tl])C(F)(F)F</smiles>

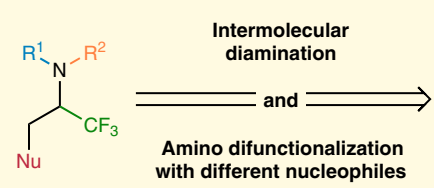

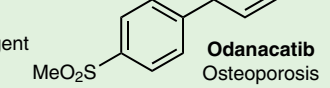

Catepshin K inis

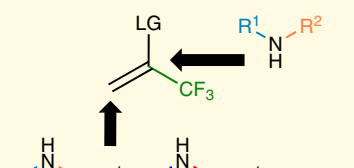

Fig. 1 General overview of ethylene diamines and trifluoromethyl amines. a Vicinal diamine backbones in natural products. $\mathbf{b}$ Pharmaceutical molecules with vicinal diamine motifs. c Alkene diamination and diazidation methodologies. d Fluoroalkylamine containing drug candidates. e Bioisosteric relations of fluoroalkylamine moiety. $\mathbf{f}$ This work: The intermolecular nucleophilic difunctionalization of a fluorinated alkene synthon provides a high degree of structural diversity of $\alpha$-trifluoromethyl diamines and substituted trifluoropropylamines in one preparative step. 


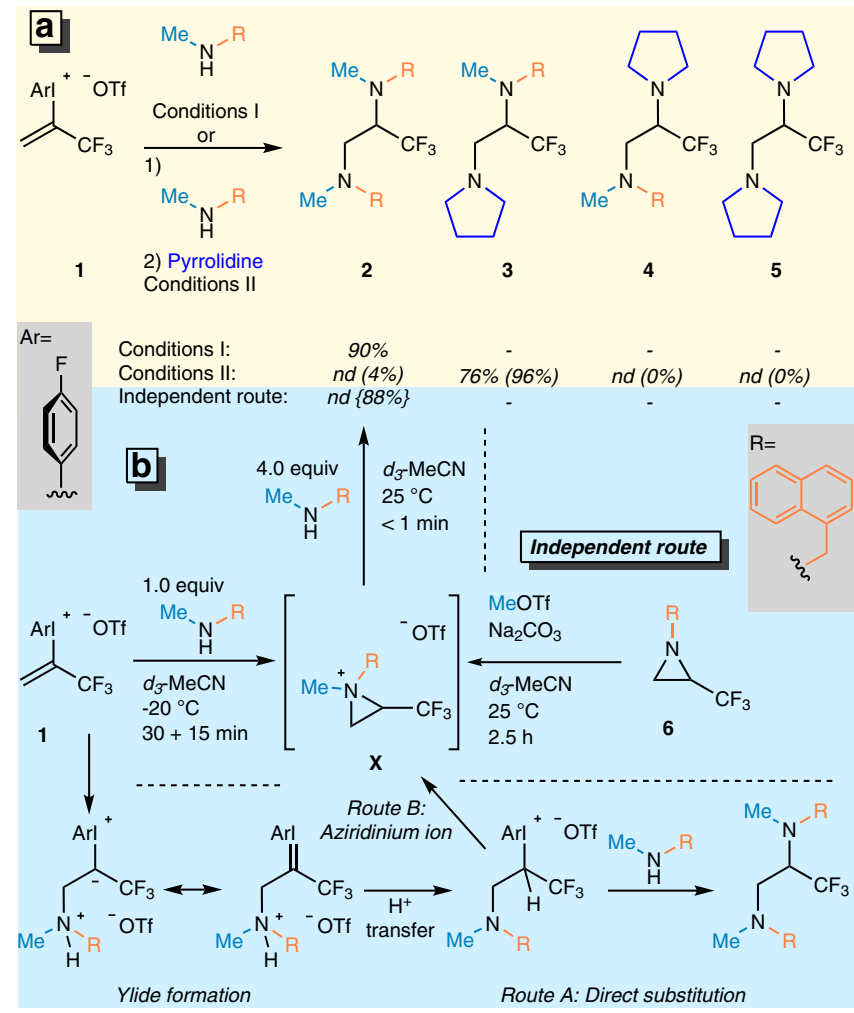

Fig. 2 Experimental mechanistic studies. a Optimized conditions of homodiamination and heterodiamination procedures and mechanistic studies. Conditions I: $1(0.20 \mathrm{mmol})$ added in one portion, $c=0.1 \mathrm{M}$, $\mathrm{MeCN}, 25^{\circ} \mathrm{C}, 1 \mathrm{~h}$. Conditions II: (1) $\mathbf{1}(0.15 \mathrm{mmol}), \operatorname{MeNHR}(0.15 \mathrm{mmol}, 1.0$ equiv.) added dropwise with syringe pump in $30 \mathrm{~min}, c=0.05 \mathrm{M}, \mathrm{MeCN}$, $-20^{\circ} \mathrm{C}, 15 \mathrm{~min}$; (2) pyrrolidine ( $0.375 \mathrm{mmol}, 2.5$ equiv.) added in one portion, $25^{\circ} \mathrm{C}, 16 \mathrm{~h}$. Yields are isolated yields; numbers given in parentheses () are GC-MS yields of products, relative to 4-F-iodobenzene. b Study of reaction intermediates and resolving their structures by independent route. Number given in \{\} represents the ${ }^{19} \mathrm{~F}-\mathrm{NMR}$ yield of $\mathbf{2}$.

group ability. Moreover, in alkenyliodonium salts ${ }^{64-68}$ the carbon-carbon bond is activated to accept nucleophiles. A perfect candidate of this reagent class for the realization of our goals is trifluoroalkenyl-iodonium salt $\mathbf{1}$ as a stable potential synthon ${ }^{69}$ allowing for the vicinal functionalization with two nucleophilic species. We expected that the secondary amine nucleophile would attach to the $\beta$-carbon due to the excellent Michael-acceptor character of the terminal $\mathrm{sp}^{2}$ carbon center and form a stabilized iodonium ylide intermediate first. After a proton transfer step, the iodonium part attached to the $\mathrm{sp}^{3}$ carbon center could act as a super leaving group and make the carbon atom more electrophilic to accept a second nucleophile. Theoretically, this step could occur intermolecularly through direct substitution by the second nucleophile (Fig. 2b, Route A) or through aziridinium ion formation (Fig. 2b, Route B) and subsequent ring opening. This is an important mechanistic question of our study.

The first attempts of the construction of the trifluoromethylated ethylene diamine backbone via diamination were performed with $\mathrm{N}$-methyl-naphthylmethylamine as the nucleophile in $\mathrm{CH}_{2} \mathrm{Cl}_{2}$ at $25^{\circ} \mathrm{C}$ in the presence of $\mathrm{Na}_{2} \mathrm{CO}_{3}$ base (Supplementary Table 1). We found that the desired homofunctionalized diamine was formed even in the presence of 1 equivalent of the amine nucleophile, albeit in $12 \%$ isolated yield. The study of different molar ratios of amine and inorganic base in various solvents led to conditions I (Fig. 2a) which ensures the isolation of the target compound 2 in $90 \%$ yield after $1 \mathrm{~h}$ reaction time. To determine the operative mechanistic path, the reaction was monitored with ${ }^{19} \mathrm{~F}-\mathrm{NMR}$ spectroscopy and complete conversion was observed within $15 \mathrm{~s}$ (Supplementary Fig. 1) in the presence of an excess amount (4 equiv.) of amine with only the ${ }^{19} \mathrm{~F}$ signal of the diaminated product observed in the spectra. In contrast, utilizing one equivalent of amine led to the formation of a diastereomeric mixture of the corresponding aziridinium ion intermediates ${ }^{70}$ (Fig. 2b and Supplementary Figs. 8-10). To prove the presence of this intermediate, we synthesized the putative aziridinium ion in situ through an independent route from aziridine $\mathbf{6}$ and MeOTf in $d_{3}-\mathrm{MeCN}$ at $25^{\circ} \mathrm{C}$ (Fig. 2b). Gratifyingly, we observed the complete consumption of aziridine $\mathbf{6}$ in $2.5 \mathrm{~h}$ and the appearance of a new signal in the ${ }^{19} \mathrm{~F}-\mathrm{NMR}$ spectra at -63.65 $\mathrm{ppm}$, which we assign to aziridinium intermediate $\mathbf{X}$ (Supplementary Fig. 10). This peak was identical with the major intermediate's signal observed in the diamination NMR experiment (Supplementary Fig. 9), and this observation supports the presence of an aziridinium ion as the key intermediate of this diamination process. We postulate that a minor intermediate also observed is the other diastereomer which cannot be formed as easily in the $\mathrm{N}$-alkylation route due to the stereoselective attack of the methyl triflate governed by the steric repulsion of trifluoromethyl group.

In the second step of the mechanistic study, the aziridinium intermediate $\mathbf{X}$ generated from aziridine $\mathbf{6}$ was reacted with 4 equivalents of $\mathrm{N}$-methyl-naphthylmethylamine (Fig. 2b), and immediate formation of the corresponding diamine 2 through ring opening was observed in the ${ }^{19} \mathrm{~F}-\mathrm{NMR}$ spectrum (Supplementary Fig. 10). This result is identical to the outcome of the reaction between the trifluoropropenyliodonium salt $\mathbf{1}$ and amine and confirms the intermediacy of aziridinium ion in the transformation.

With these experiments our key question on the mechanism was answered and the aziridinium path was confirmed. However, we aimed to expand the synthetic potential of the aziridine ring formation. The major synthetic challenge of this methodology development is the control of selectivity in the ring opening step. To overcome this challenge, we performed further optimization to develop a method for selective heterodifunctionalization reactions which afford the desired trifluoropropylamines.

In general, ring opening of substituted aziridinium ions by nucleophiles leads to mixture of constitutional isomers, which is governed by the nature of substituents of the heterocycle ${ }^{70}$. Among these substituents, the trifluoromethyl group attached to the aziridine carbon lowers the activation energy of the ring opening considerably at both $C-2$ and $C-3$ position, but in general ring opening is favored at the $C-3$ position both thermodynamically and kinetically ${ }^{71}$. Taking the advantage of the electronic influence on the ring opening could enable the selective heterodifunctionalizations of the trifluoromethyl alkenes via aziridinium intermediates. However, the implementation of this approach is challenging and requires precise control of intermediate generation. Thus, the aziridinium ion formation from the iodonium salt should be quantitative with complete consumption of 1.00 equivalent of amine. To reach this goal we optimized the reaction conditions considering addition time, concentration, and temperature (Supplementary Table 2) and found the most efficient reaction parameters culminated in conditions II. After the in situ formation of the aziridinium ion, pyrrolidine was added and the heterofunctionalized diamine 3 was isolated with high chemoselectivity and complete regioselectivity (Fig. 2a, Conditions II) in 76\% chemical yield.

Substrate scope. After the optimization studies, the scope of this homodiamination reaction was explored under the optimized 


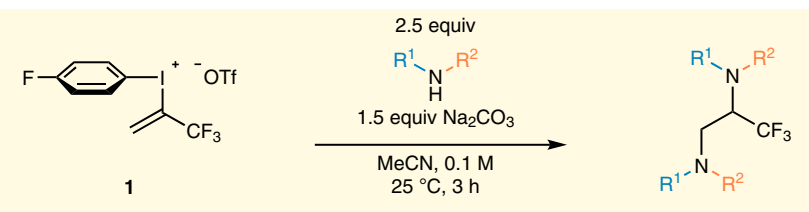<smiles>FC(F)(F)C(P)CN(c1ccccc1)c1ccccc1</smiles><smiles>FC(F)(F)C(Cn1ccc2ccccc21)n1ccc2ccccc21</smiles>
$\begin{array}{ll}\text { R } & \\ \mathrm{Me} & \mathbf{7}, 76 \% \\ \mathrm{Et} & \mathbf{8}, 13 \%\end{array}$<smiles>COc1ccccc1N(CC(N(C)C)C(F)(F)F)CC(F)(F)F</smiles>

11, $44 \%$<smiles></smiles>

R<smiles>O=[N+]([O-])N(CC(N(c1ccc(P)cc1)c1ccc(Br)cc1)C(F)(F)F)c1ccccc1</smiles>

$\begin{array}{ll}\mathrm{R} & \\ \mathrm{Me} & \mathbf{1 5}, 61 \% \\ \mathrm{Cl} & \mathbf{1 6 , 5 0 \%} \\ \mathrm{Br} & \mathbf{1 7 , 5 8 \%} \\ \mathrm{MeO} & \mathbf{1 8}, \mathbf{7 8} \%\end{array}$<smiles>CN(Cc1cccc2ccccc12)C(Cc1cccc2ccccc12)C(F)(F)F</smiles>

$19,90 \%$<smiles>[2H]CN(C[2H])CC(N(C[2H])C[2H])C(F)(F)F</smiles>

R iPr $\quad \mathbf{2 0}, 67 \%$ COOMe $\quad 22,97 \%$

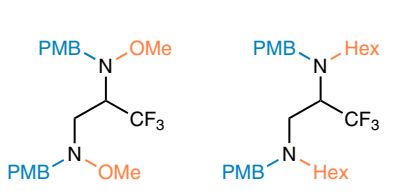<smiles>CCCCN(CC(N([18OH])C1CC1)C(F)(F)F)C1CC1</smiles><smiles>CCCN(CC(N(CC(=O)OCC)CC(=O)OCC)C(F)(F)F)C(=O)OCC</smiles><smiles>C=CCN(CC)C(N(CC=C)CCN(CC)C(=O)O)C(F)(F)F</smiles><smiles>C#CCN(P)CC([18F])N(P)CC#C</smiles><smiles>FC(F)(F)C(CN(P)CC#Cc1ccccc1)N(P)CC#Cc1ccccc1</smiles>

$23,66 \%$ $24,75 \%$ $25,83 \%$<smiles>FC(F)(F)C(CN1CCCC1)N1CCCC1</smiles>

$35^{*}, 51 \%$<smiles>FC(F)CN1CCCCN1C(F)F</smiles>

$36,67 \%$<smiles>FC(F)(F)C(CN1CC(P)C1)N1CC(P)C1</smiles>

R $\begin{array}{lr}\text { OTBS } & \mathbf{3 3}, 66 \% \\ \text { COOMe } & \mathbf{3 4}, \mathbf{7 4} \%\end{array}$

32, $66 \%$

Fig. 3 Scope of the homofunctionalized diamine synthesis. $1(0.2-0.3 \mathrm{mmol}), \mathrm{R}^{1} \mathrm{R}{ }^{2} \mathrm{NH}(2.5$ equiv. $), \mathrm{Na}_{2} \mathrm{CO}_{3}\left(1.5\right.$ equiv.), MeCN, $\mathrm{c}=0.1 \mathrm{M}, 25^{\circ} \mathrm{C}, 3 \mathrm{~h}$. ${ }^{*}$ Isolated as the corresponding bis(ammonium) trifluoroacetate salt (2 moles of trifluoroacetate ion per mole product).

conditions I. (Fig. 3) First of all, aromatic amines were evaluated regarding substituent effects on the $\mathrm{N}$-atom. The simplest, $\mathrm{N}$-Meaniline afforded diamine (7) in $76 \%$ yield, but the more sterically demanding $N$-Et-aniline performed poorly and provided diamine 8 only in $13 \%$ yield. To prove the steric sensitivity of the amine nucleophile, the cyclic analog of $\mathrm{N}$-Et-aniline, indoline was tested in the homodiamination reaction, and the corresponding diamine 9 was obtained in excellent $93 \%$ yield (reactivity of these amines was compared with ${ }^{19} \mathrm{~F}-\mathrm{NMR}$, for further details see Supplementary Figs. 2-5). Increasing the steric bulk of the cyclic nucleophile, we used six-membered tetrahydroquinoline and the corresponding diamine $\mathbf{1 0}$ has formed with considerably lower yield. The steric and electronic effects of substituents attached to phenyl ring of the aniline were investigated in case of $\mathrm{N}$-Meaniline derivatives. Although, the presence of methoxy group in ortho-position allowed the diamination and product 11 was isolated in $44 \%$ yield (Fig. 3), other tested groups in the ortho-position had a deleterious effect on the transformation (Supplementary Fig. 6). Methyl, halogen (F, Cl, Br), and methoxy functionalities are well tolerated in meta- and para-positions of the phenyl ring and the corresponding diamines (12-18) were isolated in the $39-78 \%$ yield range. Additionally, the importance of the nucleophilic character of the nucleophile was demonstrated with various anilines having electron withdrawing groups such as COOMe, $\mathrm{CF}_{3}, \mathrm{NO}_{2}$. In these cases, we were not able to obtain the desired diamines (Supplementary Fig. 6).

After the study of aniline derivatives, we used different aliphatic secondary amines. Naphthalene substituted dimethylamine afforded diamine 19 in an excellent $90 \%$ yield. Increasing the steric bulk of the amine, reactions with diisobutylamine and dibenzylamine led to $67 \%$ yields of products $(20,21)$. In contrast to the aromatic systems, the presence of an electron withdrawing ester group on the alkyl chain was well tolerated and iminodiacetic acid ester provided diamine $\mathbf{2 2}$ in almost quantitative yield. The para-methoxybenzyl (PMB) protected amines could be applied generally (23-27) and their substituent effects were studied. Regarding the electronic effects, a hydroxylamine derived nucleophile with high electron density is accepted and resulted in the isolation of the appropriate product (23) in $66 \%$ yield. The presence of a simple alkyl chain, such as $n$ hexyl, in the amine afforded product 24 in $75 \%$ yield. The highly strained cyclopropyl group could also be utilized and product $\mathbf{2 5}$ was obtained in $83 \%$ yield. The presence of an electron withdrawing ester functionality on the alkyl chain had no 
negative influence on the transformation and diamine 26 was isolated in $79 \%$ yield. The reactivity study revealed that amines with unsaturated hydrocarbon chains are also suitable for the diamination, with allyl derivative $\mathbf{2 7}$ isolated in $75 \%$ yield and the terminal and internal alkyne derivatives (28-31) could also be prepared in $\mathbf{3 8 - 9 2 \%}$ yields. Diamine 32 represents the feasibility of a $t$-butoxycarbonyl protected amine and the strained azetidinyl ring motif.

Next, saturated cyclic amines were examined from four- to seven-membered rings. In this series we could prepare the substituted azetidine derivatives (33-34) in 66 and $74 \%$ yields, respectively. Unsubstituted pyrrolidine and piperidine proved to be excellent reaction partners and products $\mathbf{3 5}$ and $\mathbf{3 6}$ were isolated in 51 and $67 \%$ yield, respectively, which suggest that ring size has little impact on the diamination. Both substituents on the piperidine ring and heteroatom replacements within the ring were also evaluated. The sterically demanding benzyl, $t$-butyldimethylsilyloxy and the homolog $t$-butyldimethyl-silyloxymethylene substituents at $C$-4 and C-3 positions are tolerated and products 37-39 were isolated in $76-89 \%$ yield. As expected, the ether functional group is tolerated as we obtained the morpholine derived diamine $\mathbf{4 0}$ in $81 \%$ yield. Both aliphatic tertiary and the 2-pyridyl substituted aza- replacements were compatible with the reaction conditions and diamines 41 and 42 were obtained in 46 and $88 \%$ yield, respectively. Additionally, the bridged 3-azabicyclo[3.2.2]nonane provided the corresponding diamine 43 in $58 \%$ yield.

To expand the applicability of the heterodiamination method under the optimized conditions II, we evaluated various amines at the first and second stages of the reaction. (Fig. 4) As a starting point we used $N$-methyl-naphthylmethylamine at the first stage of the reaction sequence to form the aziridinium intermediate $\mathbf{X}$ in situ. Ring opening of intermediate $\mathbf{X}$ is allowed by primary amine (44) at the second stage of the reaction sequence. Subsequently, we used saturated cyclic amines and found these amines can be utilized efficiently and provided the corresponding diamines $(45,46)$ in 76 and $67 \%$ yield, respectively. Further increasing the steric demands of the amine at the second stage by introducing two $i$-propyl or one 1 -adamantyl groups resulted also the formation of heterodiaminated products 47 and 48 in 54 and $72 \%$ yield, respectively. Among aromatic amines, $\mathrm{N}$-Et-aniline provided diamine 49 in good yield while the more sterically demanding and considerably less nucleophilic 2-trifluoromethyl- $N$-methylaniline was found to be reactive enough to afford $\mathbf{5 0}$ in $45 \%$ yield in the presence of di-tbutylpyridine. Still, the more complex structure of methyl N-PMB1-leucinate enables this transformation and the diastereomeric mixture of diamine derivative $\mathbf{5 1}$ was obtained in $74 \%$ yield without any difficulties. As a heterocyclic amine representative, 4-Brpyrazole was evaluated in the ring opening step, after its deprotonation, to obtain heterocyclic diamine $\mathbf{5 2}$ in $76 \%$ yield. Reactivity of imide functionality was also evaluated, thus potassium phthalimide was reacted with aziridinium intermediate and afforded the corresponding product (53) in 78\% yield. To further expand the substrate scope, we performed the heterodiamination reaction with various $N$-heterocyclic scaffolds such as indole, azaindole, benzimidazole, indazole, benzotriazole, tetrazole, deazapurine, theophylline, tryptophane, 2-mercaptopyridine, phenothiazine and isolated the corresponding heterodiaminated products (54-64) in $32-76 \%$ yield range.

Next, we examined the applicability of various amines at the first stage of the reaction while $N$-methyl-naphthylmethylamine was utilized at the second stage of the reaction sequence to gain complementary structures. Likewise to the homodiamination procedure, we started the study with the evaluation of aromatic amines, but unfortunately we could only observe the formation of the corresponding homofunctionalized diamines in the case of $\mathrm{N}$ $\mathrm{Me}$ - and $\mathrm{N}$-Et-aniline and the cyclic analog, indoline
(Supplementary Fig. 11). We, therefore, turned our attention to aliphatic amines, and the reactivity of various PMB-protected amines was studied. In this series, the cyclopropyl substituent is tolerated and derivative $\mathbf{6 5}$ was obtained in 52\% yield.

The presence of an allyl group on the amine had little impact on the efficiency as diamine $\mathbf{6 6}$ was isolated in $73 \%$ yield. Triple bonds are accepted in form of both terminal and internal alkynes, albeit, the corresponding diamines $(67,68)$ were obtained in 43 and $37 \%$ yield, respectively. It is worth noting the higher reactivity of the corresponding aziridinium intermediates in the case of propargylamines as the homodiaminated products were also formed and their separation was difficult, leading to relatively lower yields. Application of saturated cyclic amines as reactants in first stage of the reaction could lead to the formation of azaspiroammonium ions, which might possess different reactivity toward nucleophiles than previous monocyclic intermediates. Indeed, saturated cyclic amines from four- to seven-membered ring-size react in the same manner as the acyclic secondary amines. From this series, the four-membered, TBDMS protected azetidinol derivative 69 could be obtained in 53\% yield while the TBDMS protective group remained intact. The simplest five-membered pyrrolidine gave diamine $\mathbf{7 0}$ with higher efficiency (68\%). Among six-membered piperidines, 2-Me-piperidine afforded product 71 in $85 \%$ yield, despite the steric encumbrance. On the other hand, the performance of the TBDMS protected 3-piperidinol (72) was comparable to the TBDMS protected azetidinol derivative 69. $\mathrm{N}$ benzyl- (73) and N-2-pyridyl-piperazine (74) derivatives were obtained in $72 \%$ and $81 \%$ yields, respectively, in spite of the presence of additional basic $N$-atoms. Benzannulated and bridged bicyclic amines are also applicable, tetrahydroisoquinoline and the seven-membered 3-azabicyclo[3.2.2]nonane afforded diamines $(75,76)$ in $71 \%$ and $55 \%$ yields, respectively. Finally, we have demonstrated that the trifluoromethyl analog of Profenamine (77) could be assembled by the developed heterodiamination procedure.

After the extensive study of heterodiamination, we took the opportunity to expand the scope of heterofunctionalization under conditions II in the synthesis of substituted trifluoropropylamines (Fig. 5). Among the halogens, we first used the least nucleophilic fluoride ion, and successfully isolated the appropriate tetrafluoropropylamine derivative $\mathbf{7 8}$ in $65 \%$ yield. Other halides and pseudohalides were utilized in the second reaction step and the corresponding products (79-83) were isolated in $71-83 \%$ yield range. Interestingly, the 1,1,1,3-tetrafluoropropyl moiety previously had limited options in the literature for its preparation $^{50,72}$. Therefore, $N$-allyl-PMB-amine and $N$-pyrid-2-ylpiperazine were utilized to demonstrate the feasibility of conditions II in the synthesis of various tetrafluoropropylamines $(\mathbf{8 4}, \mathbf{8 5})$. We also examined the applicability of different chalcogen nucleophiles. From this series, deprotonated benzylalcohol gave derivative $\mathbf{8 6}$ in $50 \%$ yield while 4 -bromophenol and sodium benzoate afforded products $\mathbf{8 7}$ and $\mathbf{8 8}$ in 87 and $79 \%$ yield, respectively. Sulfur nucleophiles could be utilized without any additional base and cycloalkyl (89), aryl (90), and heteroaryl (91) substituted thioethers were obtained. On the other hand, applying sodium phenylsulfinate, the sulfone 92 could be accessed directly. Expanding the variety of heteroatoms at $\beta$-position, we performed the reaction with two different phosphines and prepared aminophosphanes 93, 94 having potential bidentate $N$-P ligand structure. Additionally, to prove the applicability of $C$ nucleophiles, deprotonated diethyl malonate was reacted with the aziridinium intermediate, and the corresponding malonate derivative 95 was obtained in 64\% yield. Finally, methylisoquinoline and tetrahydroquinoline were deprotonated with $n$-BuLi and converted to the corresponding trifluoroalkylamines $(96,97)$ in the $24-54 \%$ yield range, while deprotonation of indole with $\mathrm{Et}_{2} \mathrm{Zn}$ 


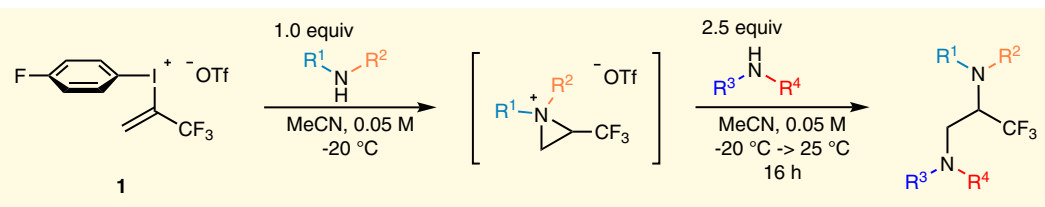

(1)

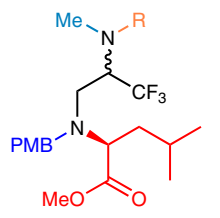

$\mathbf{5 1}, 74 \%($ d.r. $=1: 1)$<smiles>[2H]N(CC(n1nnc(-c2ccccc2)n1)C(F)(F)F)[N+](=O)[O-]</smiles>

59, $63 \%$<smiles>CN(P)CC(N([18OH])C1CC1)C(F)(F)F</smiles>

65, $52 \%$<smiles>[2H]N([N+][O-])C(Cn1cc(Br)cn1)C(F)(F)F</smiles><smiles>O=C1c2ccccc2C(=O)N1CC(N([O+])P)C(F)(F)F</smiles>

52, $76 \%$<smiles>COc1ncnc2c1ccn2CC(N([O])O)C(F)(F)F</smiles>

60, $51 \%^{\mathrm{d}}$

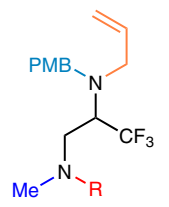

$66,73 \%$<smiles>CN(C)C(Cn1cnc2c1c(=O)n([14O])c(=O)n2C)C(F)(F)F</smiles>

$61,60 \%^{d}$<smiles>O=[N+]([O-])N(P)C(Cn1ccc2ccccc21)C(F)(F)F</smiles>

$54,76 \%{ }^{\mathrm{d}}$<smiles>O=[N+]([O-])N(P)CCn1ccc2cccnc21</smiles>

$55,48 \%^{d}$<smiles>[2H]N([O-])C(Cn1cnc2ccccc21)C(F)(F)F</smiles>

$56,42 \%^{\mathrm{d}}$<smiles>CN(C)C(Cn1ncc2ccccc21)C(F)(F)F</smiles>

57, $60 \%$<smiles>[R]N([O-])C(Cn1nnc2ccccc21)C(F)(F)F</smiles>

58, 59\%<smiles>CCOC(=O)N[C@H](Cc1cn(CC(N([O+])[O-])N(O)P)c2ccccc12)C(F)(F)F</smiles>

$62,32 \%^{d}$<smiles>[R]N([O-])C(Cn1ccccc1=S)C(F)(F)F</smiles>

$63,69 \%$ d<smiles>CN(C)C(CN1c2ccccc2Sc2ccccc21)C(F)(F)F</smiles>

$64,63 \%^{d}$<smiles>C#CCN(CCN(O)P)C(CN(O)P)C(F)(F)F</smiles>

$67,43 \%$<smiles>CC(C)CN(CC#CPc1ccccc1)C(CN(C)O)C(F)(F)F</smiles>

68, $37 \%$<smiles>[2H]N(C)CC(N1CC(OCC)C1)C(F)(F)F</smiles>

$69,53 \%$<smiles>CN(P)CC(N1CCCC1)C(F)(F)F</smiles>

$70,68 \%$<smiles>CN(C)CC(N1CCCC1[N+]([O-])(F)F)C(F)(F)F</smiles>

71, $85 \%$ (d.r.= 1.17:1)<smiles>COCCN1CCCCC1CN(C)[18OH]</smiles>

$72,58 \%$<smiles>CN(P)CC(N1CCN(Cc2ccccc2)CC1)C(F)(F)F</smiles>

$73,72 \%$<smiles>CN(CC(N1CCN(c2ccccn2)CC1)C(F)(F)F)C(F)(F)F</smiles>

74, $81 \%$<smiles>CN(C)CC(N1CCc2ccccc2C1)C(F)(F)F</smiles>

$75,71 \%$<smiles>CN(C)CC(N1CC2CCC(CC2)C1)C(F)(F)F</smiles>

76, $55 \%$<smiles>CCN(CC)C(CN1c2ccccc2Sc2ccccc21)C(F)(F)F</smiles>

$77,62 \%{ }^{d}$

Fig. 4 Scope of heterodiamination. 1st stage: $1(0.2-0.3 \mathrm{mmol})$ added at $0.3 \mathrm{mmol} \mathrm{h}{ }^{-1}$ rate, $\mathrm{R}^{1} \mathrm{R}^{2} \mathrm{NH}\left(1.0\right.$ equiv.), $\mathrm{MeCN}, c=0.05 \mathrm{M},-20^{\circ} \mathrm{C}, 0.16 \mathrm{~h}$ mmol ${ }^{-1}$; 2nd stage: $\mathrm{R}^{3} \mathrm{R}^{4} \mathrm{NH}$ or $\mathrm{Nu}$ ( 2.5 equiv.), $-20 \rightarrow 25^{\circ} \mathrm{C}, 16 \mathrm{~h}$. ${ }^{\mathrm{a}}$ Additional base: 2.5 equiv. 2,6-di-tert-butylpyridine. ${ }^{\mathrm{b}}$ Additional base: 2.5 equiv. $\mathrm{NaH}$. ${ }^{\mathrm{c} P o t a s s i u m}$ phthalimide was used. ${ }^{d}$ 2nd stage: 2.6 equiv. $R^{3} R^{4} \mathrm{NH}, 2.5$ equiv. LiHMDS, 2.5 equiv. HMPA, THF, $-78 \rightarrow 25^{\circ} \mathrm{C}, 16 \mathrm{~h}$.

gave rise to the selective alkylation at the $C-3$ position of the heteroaromatic ring to provide $\mathbf{9 8}$ in $70 \%$ yield.

\section{Discussion}

In summary, we have developed an efficient intermolecular threecomponent diamination strategy which enables the selective 1,2-difunctionalization of $\mathrm{C}-\mathrm{C}$ double bonds with two different nucleophilic agents in the absence of transition metal catalysts. Mild reaction conditions allowed the utilization of various functional groups and substitution patterns on amine nitrogen atom, providing diverse set of homo- and heterofunctionalized diamines from trifluoropropyl synthon 1. Additionally, we demonstrated the applicability of various nucleophiles such as halides, oxygen, 


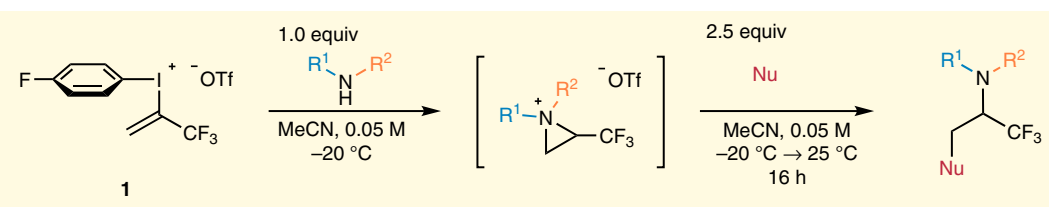

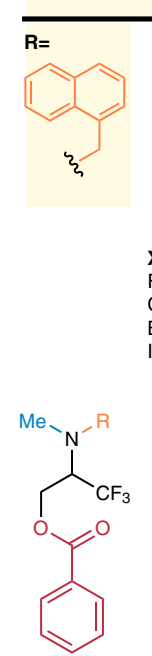

$88,79 \%^{\text {h }}$<smiles>[X]CC(N([R])C)C(F)(F)F</smiles>

$\mathbf{X}$

Cl $78,65 \%$ a

Cl $79,80 \%^{\mathrm{b}}$

$\operatorname{Br} 80,71 \%$

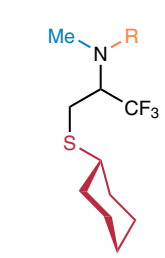

$89,78 \%$<smiles>CN(C)C(CN)C(F)(F)F</smiles>

$82,80 \%^{\mathrm{e}}$<smiles>CN(C)C(CC#N)C(F)(F)F</smiles>

83, $83 \%{ }^{\dagger}$<smiles>C=CCN(P)C(CF)C(F)(F)F</smiles>

$84,73 \%^{a}$<smiles>FCC(CF)N1CCN(c2ccccn2)CC1(F)F</smiles>

$85,64 \%^{a}$

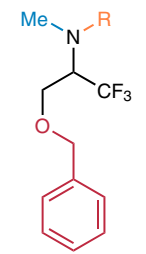

$86,50 \%^{9}$<smiles>CN(C)C(COc1ccc(Br)cc1)C(F)(F)F</smiles>

$87,87 \%^{g}$<smiles>CN(C)C(CSc1ccc(Cl)cc1)C(F)(F)F</smiles>

$90,68 \%$<smiles>CN(C)C(CSc1nc2ccccc2s1)C(F)(F)F</smiles>

91, $82 \%$<smiles>CN(C)C(CS(=O)(=O)c1ccccc1)C(F)(F)F</smiles>

$92,58 \%^{i}$<smiles>CN(C)C(CP(c1ccccc1)c1ccccc1)C(F)(F)F</smiles>

93, $57 \%$<smiles>[R]N(C)C(CP([P+](CC(F)(F)F)C12CC3CC(CC(C3)C1)C2)C12CC3CC(CC(C3)C1)C2)C(F)(F)F</smiles>

$94,65 \%$<smiles>CCCC(=O)C(CC(C)NPN)C(=O)OCC</smiles>

$95,64 \%^{\mathrm{g}}$<smiles>[CH2]C(CCc1nccc2ccccc12)N(N)P</smiles>

96, $54 \%$<smiles>[CH2+]C(CC1CCCc2cccnc21)NN</smiles>

97, $24 \%$ j (d.r. $=6.9$ :1)

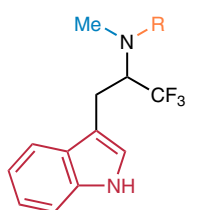

98, $70 \%{ }^{k}$

Fig. 5 Scope of trifluoropropylamines. 1st stage: $1(0.2-0.3 \mathrm{mmol})$ added at $0.3 \mathrm{mmol} \mathrm{h}^{-1}$ rate, $\mathrm{R}^{1} \mathrm{R}^{2} \mathrm{NH}(1.0$ equiv. $), \mathrm{MeCN}, \mathrm{c}=0.05 \mathrm{M},-20{ }^{\circ} \mathrm{C}, 0.16 \mathrm{~h}$ $\mathrm{mmol}^{-1}$; 2nd stage: $\mathrm{Nu}\left(2.5\right.$ equiv.), $-20^{\circ} \mathrm{C} \rightarrow 25^{\circ} \mathrm{C}, 16 \mathrm{~h}$. ${ }^{\mathrm{a} N u}=\mathrm{CsF}, \mathrm{b} \mathrm{Nu}=$ tetrabutylammonium chloride, $\mathrm{cNu}=$ tetrabutylammonium bromide, ${ }^{\mathrm{d}} \mathrm{Nu}=\mathrm{Nal}, \mathrm{e} \mathrm{Nu}=\mathrm{NaN}_{3},{ }^{\mathrm{f}} \mathrm{Nu}=\mathrm{KCN}, \mathrm{gNuH}$ was deprotonated previously by 1.0 equiv. $\mathrm{NaH}$ in $\mathrm{THF}, \mathrm{h} \mathrm{Nu}=$ sodium benzoate, ${ }^{\mathrm{i}} \mathrm{Nu}=$ sodium benzenesulfinate, ${ }^{1} 1$ st stage: $1(0.2-0.3 \mathrm{mmol})$ added at $0.3 \mathrm{mmol} \mathrm{h}{ }^{-1}$ rate, $\mathrm{R}^{1} \mathrm{R}^{2} \mathrm{NH}$ (1.0 equiv.), THF, $c=0.05 \mathrm{M}^{-}-55^{\circ} \mathrm{C}, 0.16 \mathrm{~h} \mathrm{mmol}{ }^{-1} ; 2 \mathrm{nd}$ stage: 1.1 equiv. $\mathrm{NuH}, 1.15$ equiv. $n$-BuLi in THF at $-78 \rightarrow 25^{\circ} \mathrm{C}, 16 \mathrm{~h}$. ${ }^{\mathrm{k}} 1$ st stage: $\mathbf{1}(0.2-0.3 \mathrm{mmol})$ added at $0.3 \mathrm{mmol} \mathrm{h}^{-1} \mathrm{rate} \mathrm{R}^{1} \mathrm{R}^{2} \mathrm{NH}(1.0 \mathrm{equiv}$.), MeCN, $c=0.05 \mathrm{M},-20^{\circ} \mathrm{C}, 0.16 \mathrm{~h} \mathrm{mmol}^{-1} ; 2$ nd stage: 1.2 equiv. indole, 1.2 equiv. Et $2 \mathrm{Zn}, \mathrm{PhMe}, 25^{\circ} \mathrm{C}, 16 \mathrm{~h}$.

sulfur, phosphorous and carbon nucleophiles for the synthesis of $\beta$-substituted trifluoropropylamines. The developed methodology offers a versatile synthetic tool to build high structural diversity on trifluoropropyl backbone from readily available amines and other simple nucleophiles.

\section{Methods}

General procedure for the synthesis of homofunctionalized diamines under Conditions I. An $8 \mathrm{~mL}$ vial was charged with stirring bar, appropriate amine (2.5 equiv.) and acetonitrile $(1 \mathrm{~mL} / 0.1 \mathrm{mmol})$. To the vigorously stirred mixture, sodium carbonate ( 1.5 equiv.) was added, then (4-fluorophenyl)(3,3,3-trifluoroprop-1-en-2-yl)iodonium trifluoromethanesulfonate (1) (1 equiv.) was added portionwise. The reaction mixture was stirred for $3 \mathrm{~h}$, diluted with dichloromethane and concentrated onto Celite ${ }^{\circledR}$ under reduced pressure. Residue was purified by flash column chromatography (hexanes:ethyl acetate $=100: 0 \rightarrow 50: 50$ ).

General procedure for the synthesis of heterofunctionalized diamines under Conditions II. A $30 \mathrm{~mL}$ screwed cap vial was charged with rare-earth magnetic stirring bar, 1 ( 1 equiv.) and acetonitrile $(1 \mathrm{~mL} / 0.1 \mathrm{mmol})$, then the vial was sealed with Teflon septa and screwed cap. The stirred reaction mixture was cooled to $-20^{\circ} \mathrm{C}$ (bath temp $=-23^{\circ} \mathrm{C}$ ), then solution of first amine ( 1 equiv., $0.1 \mathrm{M}$ in acetonitrile) was added dropwise $\left(0.3 \mathrm{mmol} \mathrm{h}^{-1}\right)$ by syringe pump. Subsequently, the reaction mixture was stirred for $10 \mathrm{~min} / 0.1 \mathrm{mmol}$, then the second amine or other nucleophile ( 2.5 equiv.) was added in one portion. The mixture was allowed to warm to room temperature over $16 \mathrm{~h}$, then was concentrated onto Celite under reduced pressure. The obtained residue was purified by flash column chromatography. Gradient elution was performed by using either hexanes:ethyl acetate or hexanes:diisopropyl ether eluent system, according to TLC elution experiments.

\section{Data availability}

The authors declare that the main data supporting the findings of this study are available within the article and its Supplementary Information file. Extra data are available from the corresponding author upon request.

Received: 18 May 2020; Accepted: 27 October 2020;

Published online: 23 November 2020

\section{References}

1. Lucet, D., Gall, T. L. \& Mioskowski, C. The chemistry of vicinal diamines. Angew. Chem. Int. Ed. 37, 2580-2627 (1998).

2. Kotti, S. R. S. S., Timmons, C. \& Li, G. Vicinal diamino functionalities as privileged structural elements in biologically active compounds and exploitation of their synthetic chemistry. Chem. Biol. Drug Des. 67, 101-114 (2006).

3. Viso, A., de la Pradilla, R. F., Tortosa, M., Garcia, A. \& Flores, A. Update 1 of: $\alpha, \beta$-diamino acids: biological significance and synthetic approaches. Chem. Rev. 111, PR1-PR42 (2011). 
4. McGrath, N. A., Brichacek, M. \& Njardarson, J. T. A graphical journey of innovative organic architectures that have improved our lives. J. Chem. Educ. 87, 1348-1349 (2010).

5. Jong, S. D., Nosal, D. G. \& Wardrop, D. J. Methods for direct alkene diamination, new \& old. Tetrahedron 68, 4067-4105 (2012).

6. Chong, A. O., Oshima, K. \& Sharpless, K. B. Synthesis of dioxobis(tertalkylimido)osmium(VIII) and oxotris(tert-alkylimido)osmium(VIII) complexes. Stereospecific vicinal diamination of olefins. J. Am. Chem. Soc. 99, 3420-3426 (1977).

7. Fristad, W. E., Brandvold, T. A., Peterson, J. R. \& Thompson, S. R. Conversion of alkenes to 1,2-diazides and 1,2-diamines. J. Org. Chem. 50, 3647-3649 (1985).

8. Cardona, F. \& Goti, A. Metal-catalysed 1,2-diamination reactions. Nat. Chem. 1, 269-275 (2009).

9. Wang, F.-L. et al. Catalytic asymmetric radical diamination of alkenes. Chem. 3, 979-990 (2017).

10. Conway, J. H. \& Rovis, T. Regiodivergent Iridium(III)-catalyzed diamination of alkenyl amides with secondary amines: complementary access to $\gamma$ - or $\delta$ lactams. J. Am. Chem. Soc. 140, 135-138 (2017).

11. Shen, K. \& Wang, Q. Copper-catalyzed diamination of unactivated alkenes with hydroxylamines. Chem. Sci. 6, 4279-4283 (2015).

12. Liu, R.-H., Wei, D., Han, B. \& Yu, W. Copper-catalyzed oxidative oxyamination/diamination of internal alkenes of unsaturated oximes with simple amines. ACS Catal. 6, 6525-6530 (2016).

13. Li, Y. et al. Directed copper-catalyzed intermolecular aminative difunctionalization of unactivated alkenes. J. Am. Chem. Soc. 141, 18475-18485 (2019).

14. Tao, Z., Gilbert, B. B. \& Denmark, S. E. Catalytic, enantioselective syndiamination of alkenes. J. Am. Chem. Soc. 141, 19161-19170 (2019).

15. Muniz, K. Promoting Intermolecular $\mathrm{C}-\mathrm{N}$ bond formation under the auspices of iodine(III). Acc. Chem. Res. 51, 1507-1519 (2018).

16. Röben, C., Souto, J. A., González, Y., Lishchynskyi, A. \& Muñiz, K. Enantioselective metal-free diamination of styrenes. Angew. Chem. Int. Ed. 50, 9478-9482 (2011).

17. Souto, J. A., Martínez, C., Velilla, I. \& Muñiz, K. Defined hypervalent iodine (III) reagents incorporating transferable nitrogen groups: nucleophilic amination through electrophilic activation. Angew. Chem. Int. Ed. 52, 1324-1328 (2013).

18. Muñiz, K., Barreiro, L., Romero, R. M. \& Martínez, C. Catalytic asymmetric diamination of styrenes. J. Am. Chem. Soc. 139, 4354-4357 (2017).

19. Souto, J. A. et al. Iodine(III)-promoted intermolecular diamination of alkenes. Chem. Asian J. 7, 1103-1111 (2012).

20. Qin, Q., Han, Y.-Y., Jiao, Y.-Y., He, Y. \& Yu, S. Photoredox-catalyzed diamidation and oxidative amidation of alkenes: solvent-enabled synthesis of 1,2-diamides and a-amino ketones. Org. Lett. 19, 2909-2912 (2017).

21. Reddy, T. R., Rao, D. S. \& Kashyap, S. Visible-light activated metal catalystfree vicinal diazidation of olefins with sulfonium iodate (I) species. Chem Commun. 55, 2833-2836 (2019).

22. Wang, P., Luo, Y., Zhu, S., Lu, D. \& Gong, Y. Catalytic azido-hydrazination of alkenes enabled by visible light: mechanistic studies and synthetic applications. Adv. Synth. Catal. 361, 5565-5575 (2019).

23. Govaerts, S. et al. Photoinduced olefin diamination with alkylamines. Angew. Chem. Int. Ed. 59, 15021-15028 (2020).

24. Fu, N., Sauer, G. S., Saha, A., Loo, A. \& Lin, S. Metal-catalyzed electrochemical diazidation of alkenes. Science 357, 575-579 (2017).

25. Siu, J. C., Parry, J. B. \& Lin, S. Aminoxyl-catalyzed electrochemical diazidation of alkenes mediated by a metastable charge-transfer complex. J. Am. Chem. Soc. 141, 2825-2831 (2019).

26. Khoder, Z. M., Wong, C. E. \& Chemler, S. R. Stereoselective synthesis of isoxazolidines via copper-catalyzed alkene diamination. ACS Catal. 7, 4775-4779 (2017).

27. Danneman, M. W., Hong, K. B. \& Johnston, J. N. Oxidative inter-/ intermolecular alkene diamination of hydroxy styrenes with electron-rich amines. Org. Lett. 17, 2558-2561 (2015).

28. Hong, K. B. \& Johnston, J. N. Alkene diamination using electron-rich amines: hypervalent iodine-promoted inter-/intramolecular C-N bond formation. Org. Lett. 16, 3804-3807 (2014)

29. Kaiser, D., Klose, I., Oost, R., Neuhaus, J. \& Maulide, N. Bond-forming and -breaking reactions at sulfur(iv): sulfoxides, sulfonium salts, sulfur ylides, and sulfinate salts. Chem. Rev. 119, 8701-8780 (2019).

30. Yar, M., McGarrigle, E. M. \& Aggarwal, V. K. An annulation reaction for the synthesis of morpholines, thiomorpholines, and piperazines from $\beta$ heteroatom amino compounds and vinyl sulfonium salts. Angew. Chem. Int. Ed. 47, 3784-3786 (2008).

31. Fritz, S. P., West, T. H., McGarrigle, E. M. \& Aggarwal, V. K. Diastereoselective synthesis of $\mathrm{CF}_{3}$-substituted, epoxide-fused heterocycles with $\beta$-(trifluoromethyl)vinylsulfonium salts. Org. Lett. 14, 6370-6373 (2012).
32. Hirotaki, K., Irie, A., Nakamura, Y. \& Hanamoto, T. Three-component onepot reactions of 2-trifluoromethyl- $N$-nosylaziridine, primary amines, and vinylsulfonium salts for convenient access to $\mathrm{CF}_{3}$-containing piperazines. Synthesis 49, 2488-2494 (2017).

33. Gouverneur, V. \& Müller, K. Eds., Fluorine In Pharmaceutical And Medicinal Chemistry: From Biophysical Aspects To Clinical Applications, Molecular Medicine And Medicinal Chemistry (World Scientific Publishing Company, 2012).

34. Ojima, I. Fluorine in Medicinal Chemistry and Chemical Biology (WileyBlackwell, 2009)

35. Wang, J. et al. Fluorine in pharmaceutical industry: fluorine-containing drugs introduced to the market in the last decade (2001-2011). Chem. Rev. 114 2432-2506 (2013).

36. Tomashenko, O. A. \& Grushin, V. V. Aromatic trifluoromethylation with metal complexes. Chem. Rev. 111, 4475-4521 (2011).

37. Studer, A. A. 'Renaissance' in radical trifluoromethylation. Angew. Chem. Int Ed. 51, 8950-8958 (2012).

38. Besset, T., Cédric Schneider, C. \& Cahard, D. Tamed arene and heteroarene trifluoromethylation. Angew. Chem. Int. Ed. 51, 5048-5050 (2012).

39. Charpentier, J., Früh, N. \& Togni, A. Electrophilic trifluoromethylation by use of hypervalent iodine reagents. Chem. Rev. 115, 650-682 (2014).

40. Liu, X., Xu, C., Wang, M. \& Liu, Q. Trifluoromethyltrimethylsilane: nucleophilic trifluoromethylation and beyond. Chem. Rev. 115, 683-730 (2014).

41. Zhang, N. et al. Synthesis and SAR of $[1,2,4]$ triazolo[1,5-a]pyrimidines, a class of anticancer agents with a unique mechanism of tubulin inhibition. J. Med. Chem. 50, 319-327 (2007).

42. Meanwell, N. A. Fluorine and fluorinated motifs in the design and application of bioisosteres for drug design. J. Med. Chem. 61, 5822-5880 (2018).

43. Gauthier, J. Y. et al. The discovery of odanacatib (MK-0822), a selective inhibitor of cathepsin K. Bioorg. Med. Chem. Lett. 18, 923-928 (2008).

44. Molteni, $M$. et al. $\Psi\left[\mathrm{CH}\left(\mathrm{CF}_{3}\right) \mathrm{NH}\right] \mathrm{Gly}$-peptides: synthesis and conformation analysis. Org. Biomol. Chem. 7, 2286-2296 (2009).

45. Katagiri, T., Takahashi, M., Fujiwara, Y., Ihara, H. \& Uneyama, K. General syntheses of optically active $\alpha$-trifluoromethylated amines via ring-opening reactions of $\mathrm{N}$-benzyl-2-trifluoromethylaziridine. J. Org. Chem. 64, 7323-7329 (1999).

46. Sosnovskikh, V. Y., Kutsenko, V. A., Aizikovich, A. Y. \& Korotaev, V. Y. Reactions of 3-amino-1-phenyl- and 3-amino-1-(thien-2-yl)-4,4,4trifluorobut-2-en-1-ones with 1,2-diaminopropane and 1,2-diamino-3,3,3trifluoropropane. Russ. Chem. Bull. 48, 2112-2116 (1999).

47. Prakash, G. K. S. \& Mandal, M. Stereoselective synthesis of trifluoromethylated vicinal ethylenediamines with $\alpha$-amino $\mathrm{N}$-tertbutanesulfinimines and $\mathrm{TMSCF}_{3}$. J. Am. Chem. Soc. 124, 6538-6539 (2002).

48. Xie, C. et al. Concise asymmetric synthesis of $\beta$-trifluoromethylated $\alpha, \beta-$ diamino esters through addition reactions of glycine esters to $\mathrm{CF}_{3}$ Sulfinylimine. Eur. J. Org. Chem. 7, 1445-1451 (2013).

49. Waki, M., Katagiri, T., Matsuno, K. \& Miyachi, H. Synthesis of ß-amino- $\alpha-$ trifluoromethyl- $\alpha$-amino acids exhibiting intramolecular interaction of $\mathrm{CF}_{3}$ with $\mathrm{NH}_{3}$. Tetrahedron Lett. 55, 6915-6918 (2014).

50. Neouchy, Z., Pardo, D. G. \& Cossy, J. Synthesis of optically active atrifluoromethylamines by rearrangement of $B$-amino- $\alpha$-trifluoromethyl alcohols. Org. Lett. 20, 6017-6021 (2018).

51. Fustero, S. et al. Asymmetric vinylogous Mukaiyama-Mannich reactions of heterocyclic siloxy dienes with Ellman's fluorinated aldimines. Adv. Synth. Catal. 361, 3860-3867 (2019).

52. Moens, M., Kimpe, N. D. \& D'hooghe, M. Selective synthesis of cis- and trans2-(methyl/phenyl)-3-(trifluoromethyl)aziridines and their regio- and stereospecific ring opening. J. Org. Chem. 79, 5558-5568 (2014).

53. Takehiro, Y., Hirotaki, K., Takeshita, C., Furuno, H. \& Hanamoto, T. Regioselective ring-opening reaction of 2-trifluoromethyl- $N$-tosylaziridine with some nucleophiles under basic conditions. Tetrahedron 69, 7448-7454 (2013).

54. Kuzmich, D. et al. Function-regulating pharmacophores in a sulfonamide class of glucocorticoid receptor agonists. Bioorg. Med. Chem. Lett. 23, 6640-6644 (2013).

55. Yang, L. et al. Synthesis of $\alpha-\mathrm{CF}_{3}$ and $\alpha-\mathrm{CF}_{2} \mathrm{H}$ amines via the aminofluorination of fluorinated alkenes. Chem. Commun. 54, 5907-5910 (2018).

56. Yoshimura, A. \& Zhdankin, V. V. Advances in synthetic applications of hypervalent iodine compounds. Chem. Rev. 116, 3328-3435 (2016).

57. Olofsson, B., Ilan, M. \& Zvi, R. The Chemistry of Hypervalent Halogen Compounds. Patai's Chemistry of Functional Groups (Wiley-Blackwell, 2019).

58. Merritt, E. \& Olofsson, B. Diaryliodonium salts: a journey from obscurity to fame. Angew. Chem. Int. Ed. 48, 9052-9070 (2009).

59. Li, Y., Hari, D. P., Vita, M. V. \& Waser, J. Cyclic hypervalent iodine reagents for atom-transfer reactions: beyond trifluoromethylation. Angew. Chem. Int. Ed. 55, 4436-4454 (2016). 
60. Zhdankin, V. V. Hypervalent Iodine Chemistry (John Wiley \& Sons Ltd, 2013).

61. Phipps, R. J. \& Gaunt, M. J. A meta-selective copper-catalyzed C-H bond arylation. Science 323, 1593-1597 (2009).

62. Taylor, M. T., Nelson, J. E., Suero, M. G. \& Gaunt, M. J. A protein functionalization platform based on selective reactions at methionine residues. Nature 562, 563-568 (2018).

63. Modha, S. G. \& Greaney, M. F. Atom-economical transformation of diaryliodonium salts: tandem $\mathrm{C}-\mathrm{H}$ and $\mathrm{N}-\mathrm{H}$ arylation of indoles. J. Am. Chem. Soc. 137, 1416-1419 (2015).

64. Pirkuliev, N. S., Brel, V. K. \& Zefirov, N. S. Alkenyliodonium salts. Russ. Chem. Rev. 69, 105-120 (2000).

65. Stridfeldt, E. et al. Synthesis, characterization and unusual reactivity of vinylbenziodoxolones - Novel hypervalent iodine reagents. Chem. Eur. J. 22, 16066-16070 (2016)

66. Tóth, B. L. et al. Synthesis of multifunctional aryl(trifloxyalkenyl)iodonium triflate salts. ACS Omega 4, 9188-9197 (2019).

67. Wu, J., Deng, X., Hirao, H. \& Yoshikai, N. Pd-Catalyzed conversion of alkynyl- $\lambda^{3}$-iodanes to alkenyl- $\lambda^{3}$-iodanes via stereoselective 1,2 -iodine(III) shift/1,1-hydrocarboxylation. J. Am. Chem. Soc. 138, 9105-9108 (2016).

68. Ding, W., Chai, J., Wang, C., Wu, J. \& Yoshikai, N. Stereoselective access to highly substituted vinyl ethers via trans-difunctionalization of alkynes with alcohols and iodine(III) electrophile J. Am. Chem. Soc. 142, 8619-8624 (2020).

69. Mészáros, Â., Székely, A., Stirling, A. \& Novák, Z. Design of trifluoroalkenyl iodonium salts for a hypervalency-aided alkenylation-cyclization strategy: metal-free construction of aziridine rings. Angew. Chem. Int. Ed. 57, 6643-6647 (2018).

70. Stankovic, S. et al. Regioselectivity in the ring opening of non-activated aziridines. Chem. Soc. Rev. 41, 643-665 (2012).

71. Cherni, E., Essalah, K., Besbes, N., Abderrabba, M. \& Ayadi, S. Theoretical investigation of the regioselective ring opening of 2-methylaziridine. Lewis acid Effect. J. Mol. Model. 24, 309 (2018).

72. Xie, C. et al. Detrifluoroacetylative in situ generation of free 3-fluoroindolin-2one-derived tertiary enolates: design, synthesis, and assessment of reactivity toward asymmetric Mannich reactions. Org. Lett. 18, 3270-3273 (2016).

\section{Acknowledgements}

The authors thank the support of National Research, Development and Innovation Office (Grant No. K125020 and 2018-2.1.7-UK_GYAK-2019-00001) for support of this research, Dr. Ágnes Gömöry at Research Center for Natural Sciences, Budapest, Hungary for HRMS measurements, Professor Tibor Soós and Mr. Kristóf Hegedüs at Research Center for Natural Sciences, Budapest, Hungary for providing several heterocycles,

Dr. Szilárd Varga and Mr. Máté Berta at Research Center for Natural Sciences, Budapest,
Hungary for multidimensional NMR measurements, Professor Brian M. Stoltz, Dr. Scott Virgil, and Mr. Tyler J. Fulton at Caltech for proofreading of the paper. This work was completed in the ELTE Institutional Excellence Program supported by the National Research, Development and Innovation Office (NKFIH-1157-8/2019-DT).

\section{Author contributions}

F.B., Á.T., B.B., and Á.M. performed the experiments. F.B. and Z.N. designed the mechanistic studies, chemical space of substrate scope, and wrote the paper. Z.N. conceptualized and directed the research.

\section{Competing interests}

The authors declare no competing interests.

\section{Additional information}

Supplementary information is available for this paper at https://doi.org/10.1038/s41467020-19748-z.

Correspondence and requests for materials should be addressed to Z.N.

Peer review information Nature Communications thanks the anonymous reviewer(s) for their contribution to the peer review of this work.

Reprints and permission information is available at http://www.nature.com/reprints

Publisher's note Springer Nature remains neutral with regard to jurisdictional claims in published maps and institutional affiliations.

(c) (i) Open Access This article is licensed under a Creative Commons BY Attribution 4.0 International License, which permits use, sharing, adaptation, distribution and reproduction in any medium or format, as long as you give appropriate credit to the original author(s) and the source, provide a link to the Creative Commons license, and indicate if changes were made. The images or other third party material in this article are included in the article's Creative Commons license, unless indicated otherwise in a credit line to the material. If material is not included in the article's Creative Commons license and your intended use is not permitted by statutory regulation or exceeds the permitted use, you will need to obtain permission directly from the copyright holder. To view a copy of this license, visit http://creativecommons.org/ licenses/by/4.0/.

(C) The Author(s) 2020 